Rev. Fac, Med. vet. Zootec. Univ. S. Paulo

$11: 21-5,1974$

\title{
POLPA CITRICA PELETIZADA PARA BOVINOS EM CONFINAMENTO
}

Lício VELLOSO *

Noé MASOTTI **

Manoel BECKER ***

Carlos S. LUCCI **

RFMV-A/2

Velloso, L. et al. - Polpa cítrica peletizada para bovinos em confinamento.

Rev. Far. Med. vet. Zootec. Univ. S. Paulo, $11: 21-5,1974$

Resumo: A polpa cítrica "peletizadu" substituiu parcial e totalmente as espigas de milho desintegradas num experimento de blocos ao acaso, com tres tratumentos e seis repetiçoes, totalizando 18 bovinos mestiços holandezes. todos machos inteiros e com idade inicial aproximada de 17 meses. Após 140 dias experimentais. os animais apresentaram, em média, os seguintes yanhos em peso, diários: $A=0,792 \mathrm{~kg} ; B=0,957 \mathrm{~kg}$ e $C=0,992 \mathrm{~kg}$. Os pesos médios dos animuis, inicial e final, foram respectivamente: $A=244,0$ e $355.0 \mathrm{~kg} ; B=246,0$ e $380,0 \mathrm{~kg} ; C=244,0$ e $383,0 \mathrm{~kg}$. Houve diferenca estatistica significtua ao nivel de $5 \%$ de probabilidade e pelo teste de Duncan, os tratamentos $B$ e $C$ foram superiores ao tratamento $A$, porém iguais entre si.

Unitermos: Polpa cítrica*; Confinamento*; Engorda *; Bovinos*.

\section{INTRODUCÃO E LITERATURA}

As indústrias paulistas de extração de suco citrico, têm aumentado consideravelmente suas produções. Como conseqüência, tem havido disponibilidade de grande quantidade de polpa, que se fosse toda submotida aos processos de secagem e "peletização" proporcionaria mais de 200 mil toneladas de polpa "pelctizarla" anualmente. O aproveitamento deste sub-produto na alimentação animal notadamente de bovinos. é perf(sitamente viável como substituto parcial ou total do desintegrado de milho (grãos, palhas e sabugos). Esta utilizaçāo da polpa citrica poderá representar fator ponderável na economia agricola do Estado de São Paulo e do Brasil.

Num excelente trabalho de revisão da literatura, efetuado por KIRK \& KOGER ' (1970), das pesquisas efetuadas entre 1946 e 1960, várias e interessantes conclusōes foram tiradas: 1) a polpa citrica é fonte rica em energia. podendo constituir-se no principal alimento energético para bovinos de qualquer categoria; 2) mistura-se

* Professor Assistente Doutor.

* I'rocessor I,ivre Docente. Dẹpartamento de I’roducão Animal da Faculdade de Medicina Veterináría e Zootecnia da USP.

*** Engenheiro Agrönomo. I'esquisador Científico do Instituto de Zootecnia da Secretaria da Agricultura. são I’aulo. 
VELloso, L. et al. - Polpa cítrica peletizada para bovinos em confinamento. Rev. Fac. Med. vet. Zootec. Univ. S. Paulo, 11:21-5, 1974.

facilmente com outros ingredientes na raçāo; 3) devido a sua densidade, reduz os distúrbios digestivos ao mínimo; 4) favorece a formação de carcaça de boa qualidade.

GOHL' (1972), afirmou que além da excelência apresentada pela polpa citrica desidratada como fonte de energia e melhoradora da palatabilidade para bovinos, exerce ainda suave efeito laxante. KIRK \& DAVIS ${ }^{3}$ (1954), já haviam concluído que a polpa cítrica seca poderá compor parte considerável dos nutrientes energéticos para mantença ou para engorda de bovinos.

Trabalhando com ovinos, BHATTACHARYA \& HARB ${ }^{1}$ (1973), notaram que à medida que aumentaram o teor de polpa cítrica seca em substituição ao milho até - nível de $60 \%$ da ração, houve correspondente aumento na digestibilidade da porção fibrosa da ração; contudo, caiu ligeiramente a ingestāo de alimento, notadamente quando o nivel de polpa cítrica desidratada ultrapassou de $40 \%$ do total da ração. WELCH \& SMITH 7 (1971), estudaram o efeito da polpa citrica seca na atividade ruminal de bovinos e ovinos, concluindo que houve redução no tempo de ruminação dos animais alimentados apenas com aquele sub-produto industrial. SCHAIBLY \& WING " (1974) estudaram o efeito da substituição parcial e total da silagem de milho pela polpa cítrica fornecidas a bovinos. Concluiram que houve aumento na digestibilidade da matéria seca e da energia, quando esta substituição ocorreu até o nível de $2 / 3$.

O objetivo do presente trabalho foi estudar a viabilidade técnica e econômica do emprego da polpa cítrica peletizada em substituição ao desintegrado de milho (grãos, palhas e sabugos) nas rações de bovinos para o abate, mantidos em confinamento.

\section{MATERIAL E MÉTODOS}

Seguindo o delineamento de blocos ao acaso, com três tratamentos e seis parcelas, de acordo com LI ${ }^{5}$ (1964), foram utilizados 18 bovinos mestiços holandezes, machos inteiros e com idade aproximada de 17 meses, ao inicio do experimento, para estudar a viabilidade técnica e econômica da utilização da polpa cítrica "peletizada" nas rações destinadas à engorda daqueles animais em regime de confinameno (tabela I).

T A B E L A I

Racōes experimentais

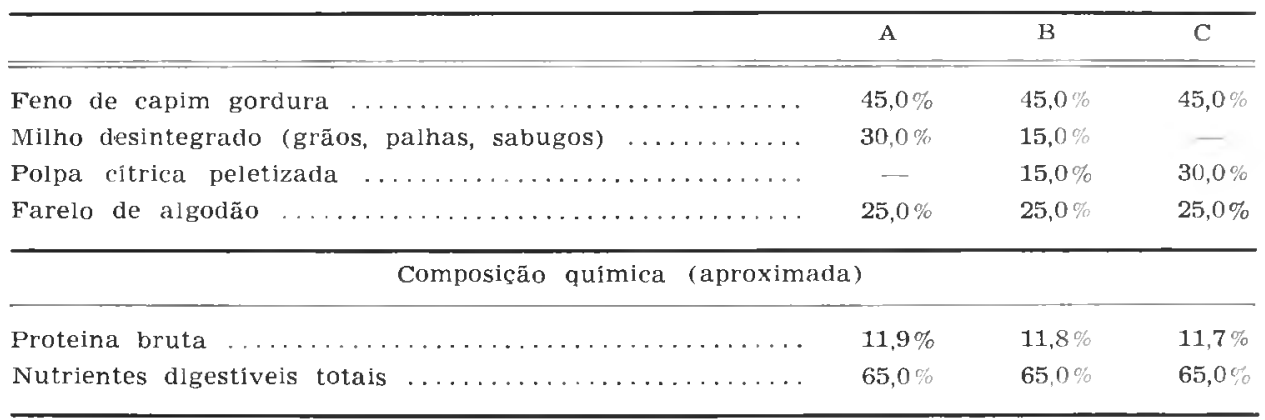

Os animais tiveram a todo instante ração à vontade nos cochos, exceto nas 18 horas que antecediam às pesagens, quando então observava-se jejum completo, de ração e água. As pesagens foram realizadas cada 28 dias, sempre no periodo compreen- 
VElloso, L. et al. - Polpa cítrica peletizada para bovinos em confinamento. Rev. Fac. Med. vet. Zooter. Univ. S. Paulo, 11:21-5, 1974.

dido entre 8:00 e 9:00 h. O controle do consumo das rações foi efetuado diariamente. Sal mineralizado completo foi fornecido, à vontade, em cochos apropriados.

Em razão da má qualidade do feno de capim gordura (Melinis Minutiflora) decidiu-se pela administração parenteral de um complexo vitamínico $\mathrm{AD}_{3} \mathrm{E}$, de acordo com o peso do animal, a cada 60 dias; também contribuiu para esta decisão o fato dos animais terem permanecido em galpão inteiramente fechado e coberto, embora com acesso ao solário externo, diariamente por 1 hora, durante a limpeza das instalações.
Banhos carrapaticidas e bernicidas foram aplicados, por aspersão, sempre que julgados necessários.

\section{RESULTADOS E DISCUSSAO}

Após 140 dias experimentais, os bovinos apresentaram os ganhos em peso, constantes da Tabela II. Os pesos médios dos animais, inicial e final, foram respectivamente: $\mathrm{A}=244,0$ e $355,0 \mathrm{~kg} ; \mathrm{B}=246,0$ e $380,0 \mathrm{~kg}$ e $\mathrm{C}=244,0$ e $383,0 \mathrm{~kg}$. Os ganhos em peso, médios diários, foram: $\mathrm{A}=0.792 \mathrm{~kg} ; \mathrm{B}=0,957 \mathrm{~kg}$ e $\mathrm{C}=$ $0,992 \mathrm{~kg}$.

TA B E L A I I

Ganhos em peso durante os 140 dias experimenta's.

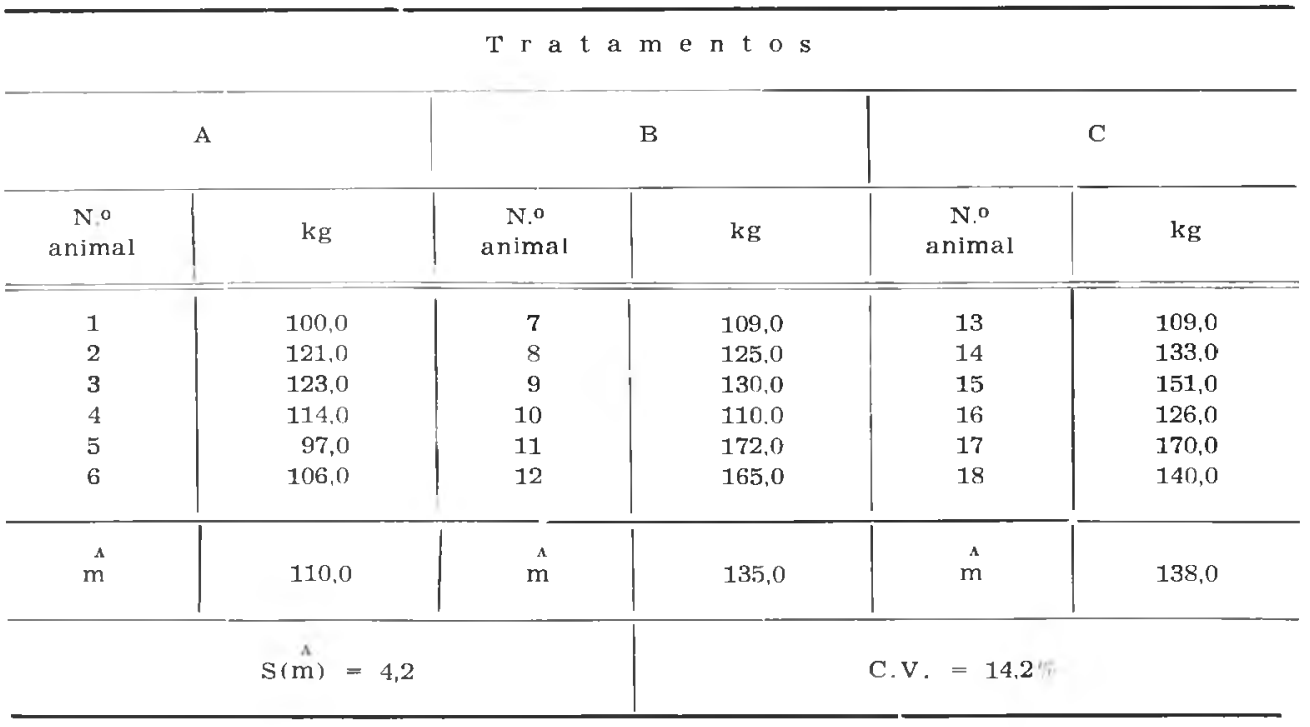

Os consumos médios das rações durante o experimento foram : $\mathrm{A}=1.386 \mathrm{~kg} ; \mathrm{B}$ $=1.570 \mathrm{~kg}$ e $\mathrm{C}=1.551 \mathrm{~kg}$.

As conversões alimentares, por tratamento, foram respectivamente: $\mathrm{A}=$ $12,590: 1 ; \mathrm{B}=11,626: 1$ e $\mathrm{C}=11,232: 1$.

Os dados referentes aos ganhos em peso, foram submetidos à análise estatística, tendo revelado diferença significativa ao ní- vel de $5 \%$ de probabilidade. Posteriormente as médias foram comparadas pelo teste de Ducan, notando-se que os tratamentos $B$ e $C$ superaram o tratamento $A$, porém foram iguais entre si. Embora não tenha havido diferença entre os tratamentos $B$ e $C$, pode-se notar pelo exame das médias dos ganhos em peso, que houve efeito quase linear da polpa cítrica sobre 
VELloso, I. et al. - Polpa citrica peletizada para bovinos em confinamento. Rev. Fac. Med, vet. Zootec. Univ. S. Paulo, 11:21-5, 1974.

o desenvolvimento dos animais; isto é, à medida que foi aumentado o nível da polpa citrica peletizada na raçāo até o nivel de $30 \%$ houve quase correspondente aumento no ganho em peso. Estes resultados estão em perfeito acordo com os dizeres de KIRK \& KOGER 1 (1970) e KIRK \& DAVIS $: 3$ (1954). Também os resultados obtidos por BHATTACHARYA \& HARB 1 (1973) quanto ao nivel adequado de polpa cítrica seca nas raçōes de ruminantes, ajustam-se perfeitamente aos do presente trabalho. O mesmo pode ser dito dos achados de SCHAIBLY \& WING ' (1974), principalmente se forem examinados os dados de conversāo alimentar encontrados no experimento em discussāo.

\section{O N C L L S O E S}

Os resultados obtidos neste experimento demonstraram que tecnicamente é vantajosa a substituição do desintegrado de milho pela polpa cítrica peletizada, nas rações de bovinos para o abate, mantidos em regime de confinamento, quando o limite máximo deste resíduo industrial atinge a $30 \%$ do total da raçāo.
Economicamente também pode-se concluir pela viabilidade do uso da polpa cítrica "peletizada" para bovinos, quando se desejar uma resposta em peso mais marcante, pois embora seja um produto de custo ligeiramente mais elevado que o desintegrado de milho, proporciona ganhos em peso, mais expressivos e conversão alimentar mais estreita, o que representa economia de raçāo e de tempo durante o processo de engorda.

Os animais que foram levados ao confinamento com peso médio de $245 \mathrm{~kg}$ e idade ao redor dos 17 meses, atingiram o peso mérlio final de quase $380 \mathrm{~kg}$ antes dos 22 meses de idade, comprovando mais uma vez que na região do Brasil-Central há condições técnicas para serem produzidos bovinos para o corte com 15 arrobas antes dos 2 anos de idade.

\section{A G R A D E C I M E N T O S}

Os autores agradecem às firmas Citrosuco Paulista S.A.; Citrobrasil S.A. e Baby-Bef Rubaiyat S.A. pelo suporte material proporcionado à execuçāo deste trabalho.

$\mathrm{RFMV}-\mathrm{A} / 2$

Velloso, L. et al. Dried citrus pulp for fattening cattle, Rev. Fas. Med. vet. Zootec. Univ. \&. Paulo, 11:21-5, 1974

Summary: During 140 experimental days, ground pelleted citrus pulp replaced ground corn ears in rations for fattening cattle. Ration A, contaneded no citrus pulp and $30 \%$ ground corn ears; rations $B$, contuined $15 \%$ from each of them and ration $C$. contained $30 \%$ citrus pulp and no ground corn ears.

Average daily gains were: $A=.792 \mathrm{~kg} ; B=.957 \mathrm{~kg}$ and $C=.992 \mathrm{~kg}$. Heed conversions were: $A=12.590: 1 ; B=11.626: 1$ and $C=$ 111.232:1

Weight gains data underwent statistical analysis followed by Duncans procedure which declured treatments $B$ and $C$ greater than treatment $A$. but equal between themselves.

These results suggest that dried citrus pulp is a good replacer for ground corn ears in rations for fattening cattle.

Unitermos: Citrus pulp*; Confinent*; Futtening catlle*: Weight gains*. 
VELloso. L. et al. - Polpa cítrica peletizada para bovinos em confinamento. Rev. Far. Mea. vet. Zootec. Univ. S. Paulo, 11:21-5, 1974.

\section{REFERENCIAS BIBLIOGRAFICAS}

1. BHATTACHARYA, A. N \& HARB M Dried citrus pulp as a grain replacement for awasi lambs. J. Anim. Sci., 3(i $(6): 1175-80,1973$.

2. GOHI, B. I. - Los subproductos de los citrus para la alimentacion del ganado. Zootecnua, 6:24-7, 1972.

3. KIRK, W, G. \& DAVIS, G. K. - Citrus products for beef ('attle. Ext. Bull. Flu. agric. Kxp. Sith., (538) 1954.

4. KIRK, W. G. \& KOGER, M. - Citrus products in rattle finishing rations: a review of resear'h at range catte sation (1946-60). Ext. Bull. Fla. agric. Exp. Stn., (739) 1970 .
5. LI C C. - Introduction to experimental statistics. New York, McGraw Hill, Book, 1964. p. 460 .

6. SCIIAIBLY, G. E. \& WING, J , M Efrect of roughage concentrate ratio on digestibility and rumen fermentation of corn silage-citrus pulp rations. J. Anim. Sci., 38(3):697-701. 1974

7. WELCH, J. G. \& SMITI1, A. M. Effert of beef pulp and citrus pulp on rumination activity. J. Anim. Sci., 33 (2) : 472-75, 1971.

Recebido para publicacāo em 28-8-74 Aprovado para publicacão em 29-8-74 